[President's page ]

\title{
The Belgian Society of Cardiology: a view on its strength, weakness, opportunities and threats
}

\author{
Victor LEGRAND, MD, PhD \\ BSC president 2011-2012
}

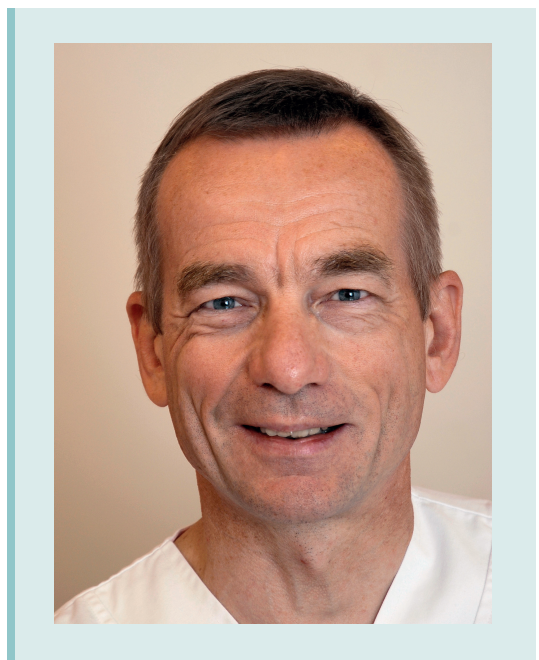

\author{
During the last \\ thirty years, our \\ Society, the Bel- \\ gian Society of \\ Cardiology (BSC), \\ - Priority on education and research development \\ - Presence in the regulatory environment \\ - Improvement of our visibility \\ - Collaboration with allied professional and scientific \\ societies
} has emerged as a scientific, organizational and professional structure that is now the undisputed head of Belgian cardiologists. The experience, devotion and personal qualities of my predecessors contributed largely to the success and development of our Society which I am proud to chair for the upcoming two years. Our goal will be to continue along their successful path in touch with current scientific, social, economic and political developments. Achievement of our leadership will be conducted in close collaboration with all constituents of the board of which the structure ensures an adequate equilibrium between academic and non-academic cardiologists, sub-specialities, private and hospital practice and cultural differences ensuring a democratic representation of all constituent bodies of our society.

My main priorities as President are described briefly below. Of course, these delineate a range of ideas and intentions that will need to be modified in accordance with the prevailing circumstances.

\section{MY MAIN PRIORITIES AS PRESIDENT:}

- Some specific topics that will be taken into consideration are:

\section{The BSC and education}

Education and research have always been the core business of all scientific organizations. It is clear that the BSC has a central role in coordinating and promoting not only postgraduate continuous education, but also in supporting efforts of working groups to develop educational courses in their specific subspecialities. Lack of adequate funding to set up educational programmes and industry-based education may represent weakness and threats. To avoid conflict of interest and ensure a high scientific level of education, a close collaboration between our society and the industry is needed.

Success of the recent $30^{\text {th }}$ meeting of our society reflects this ambition to set up a national organization of a high scientific and educational level in close collaboration with the industry. Similar initiatives should be taken by different working groups to teach treatments or techniques not only to young fellows but also to all interested cardiologists.

Similarly, fundamental as well as clinical research in cardiology should be encouraged through a better promotion of the different awards already distributed through or by the BSC (BSC Young Investigator award, Meda Pharma prize, Dumont prize, Bernheim prize).

\section{The BSC and the socio-political partners}

We have many reasons to be pessimistic in the immediate future about our relations with authorities. In times of economic recession, we should expect to be faced with budgetary restrictions. Additionally, ongoing therapeutic 
and technical developments allow new treatment even more expensive which will be difficult to adopt readily in practice. Another threat is a lower priority for the prevention and treatment of cardiovascular diseases in the policy of the health care.

To face these challenges we have to strengthen our presence at the different political and socio-economic levels and become not only the scientific delegate of the cardiology community, but also the interlocutor of all Belgian cardiologists at the decision level, in collaboration with medical unions and professional associations.

\section{The BSC in the electronic era}

Electronic media are part of our everyday life and should be used more extensively not only to increase our visibility but most importantly to distribute relevant information, to improve our collaboration, to set up a real cardiology network and to foster a melting pot of new ideas.

How to achieve these ambitious objectives is one of the most difficult challenges of my presidency. Opportunities exist to set up a convivial BSC forum where all cardiologists could find the most relevant and pertinent information, in collaboration with the industry and/or other scientific organizations, however.

\section{The BSC and the allied societies}

We have to improve our collaboration with professional, public and scientific associations dealing with cardiovascular problems. Collaboration and partnership is strategically essential. This is true, not only for reimbursement or health care management issues as stated above, but also for scientific matters (collaboration with other scientific societies like BACTS, ESC, SFC, etc.) and general public education (Ligue Cardiologique Belge, e.g.). By doing this, we reinforce our influence at the scientific, public and political level and we aim to a better implementation of cardiologic recommendations at the national level.

My ultimate goal will not only be to defend and develop our profession, but foremost, like my predecessor, to build up the spirit of brotherhood and conviviality in a democratic way.
Prof. Victor Legrand Department of Cardiology CHU de Liège, Liège 